\title{
Wolff-Parkinson-White syndrome (type A) complicated by heart block in both normal and accessory pathways
}

\author{
A. F. MACKINTOSH, D. A. CHAMBERLAIN, AND P. V. L. CURRY, \\ From the Departments of Cardiology, Royal Sussex County Hospital, Brighton, \\ King's College Hospital, London, and Hammersmith Hospital, London
}

SUMMARY A 67-year-old man with Wolff-Parkinson-White syndrome type A presented with second degree atrioventricular block in the anomalous pathway and complete infra-Hisian block in the HisPurkinje pathway. He had increasingly frequent attacks of dizziness not related to exercise. A permanent ventricular demand pacemaker was successfully implanted following intracardiac electrophysiological studies.

Disorders of conduction occurring simultaneously in both normal and abnormal atrioventricular pathways of patients with the Wolff-Parkinson-White syndrome have only rarely been observed (Lev et al., 1966). Intracardiac studies to reveal the underlying electrophysiological mechanisms have been undertaken in a few such cases with iatrogenic or congenital (nodal) atrioventricular block in the nodalHis-Purkinje pathway (Coumel et al., 1973; Seipel et al., 1976).

We report a case of Wolff-Parkinson-White syndrome type A presenting with episodes of dizziness caused by combined conduction abnormalities in both the normal and the accessory atrioventricular pathways. An unusual feature was that the normal pathway was blocked below the His bundle.

\section{Case report}

A 67-year-old man was referred with transient episodes of dizziness over a period of 6 years. Attacks occurred at rest and were not induced by exercise. No episodes of complete syncope had occurred and there was no history of paroxysmal tachycardia in childhood or adult life.

An electrocardiogram showed Wolff-ParkinsonWhite syndrome type A with maximal ventricular pre-excitation, intermittent second degree atrioventricular block and a PR (P-delta) interval of $0.14 \mathrm{~s}$ for conducted sinus beats (Fig. 1). Second degree atrioventricular block usually followed slowing of

'Present address: Department of Cardiology, Guy's Hospital, London.

${ }^{2}$ In receipt of a British Heart Foundation grant. the sinus rate. His bundle recordings (Scherlag et al., 1969) showed intermittent 2:1 conduction of sinus beats across the accessory pathway when the atrial rate fell below 80 per minute. Conducted sinus beats were preceded by a His potential with an $\mathrm{HV}$ interval (His spike to earliest ventricular activity) of $25 \mathrm{~ms}$. Sinus beats not conducted in the accessory pathway were completely blocked after the His potential (infra-Hisian block, Fig. 2A). Right atrial pacing at a cycle length of $485 \mathrm{~ms}$ (124 beats/min) induced a normal atrioventricular response, the $\mathrm{AH}$ interval increasing from $120 \mathrm{~ms}$ (upper limit of normal range) during spontaneous rhythm to $155 \mathrm{~ms}$. The apparent $\mathrm{HV}$ interval of conducted beats shortened from $25 \mathrm{~ms}$ to $0 \mathrm{~ms}$ during incremental atrial pacing, without further widening of the QRS complex. Ventricular activation never occurred by the normal pathway. Oneto-one anterograde accessory pathway conduction occurred at atrial pacing rates up to 150 beats per minute, during which the A-delta conduction interval increased from 145 to $155 \mathrm{~ms}$ (Fig. 2B). Ventricular pacing showed no retrograde conduction in either the normal or accessory pathway.

A permanent ventricular demand pacemaker was implanted, initially with an endocardial electrode but this was unstable and was later replaced by an epicardial one. The patient has had no more attacks of dizziness (follow-up 9 months).

\section{Discussion}

In patients with the Wolff-Parkinson-White syndrome and sinus rhythm the ventricle is activated 
II
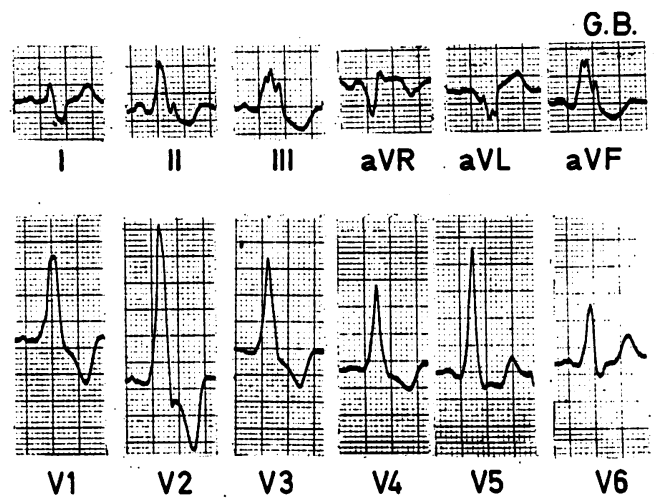

Fig. 1 Electrocardiogram in spontaneous rhythm showing second degree block and pattern of pre-excitation.

(A)

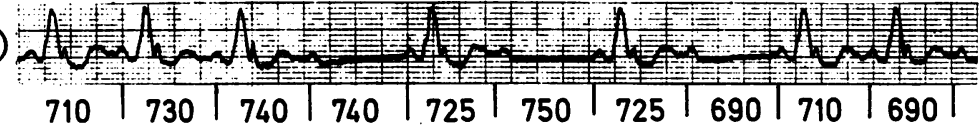

(B)

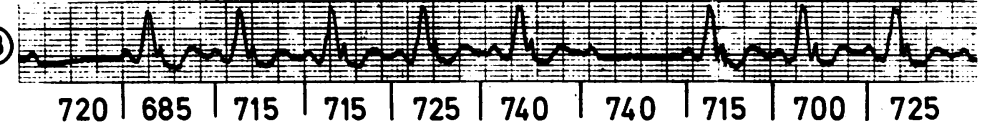

(A)
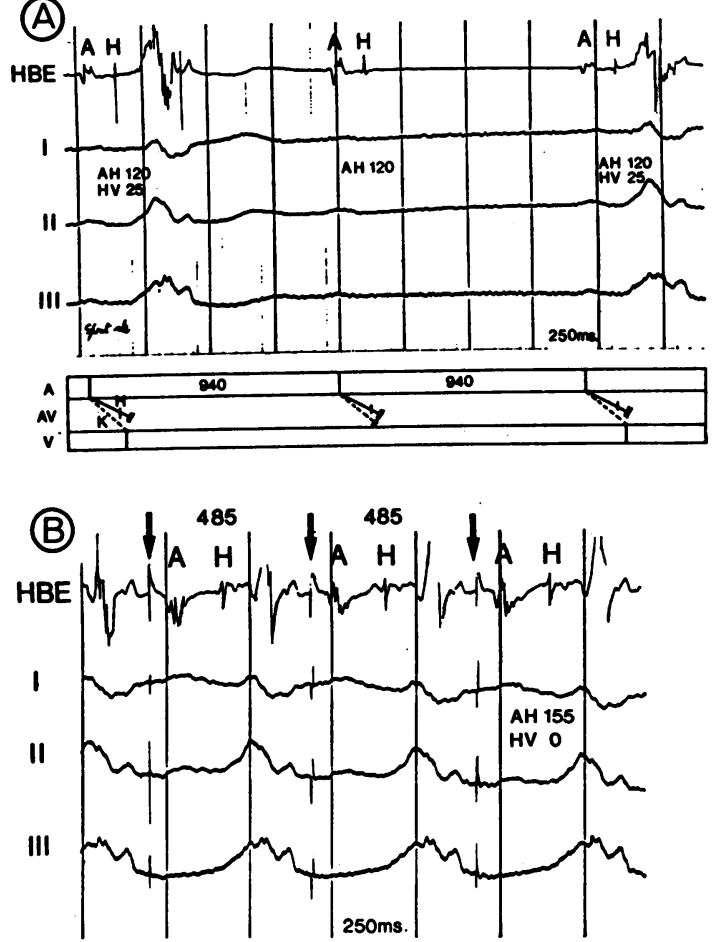

Fig. 2 His bundle electrogram (HBE) and three surface leads. (A) spontaneous rhythm; $(B)$ atrial pacing at 124 beats per minute. Conduction is now 1:1. $H V$ interval is now zero but the QRS morphology is unchanged indicating that conduction must be down the aberrant pathway in sponataneous rhythm and with atrial pacing. 
typically via two atrioventricular pathways; one is the normal His-Purkinje pathway and the other is the abnormal accessory pathway. The QRS configuration of the fusion beats recorded on the surface electrocardiogram indicates the relative times required for sinus impulses to be conducted to the ventricle 'in parallel' down both the normal and accessory atrioventricular pathways. Usually both incremental atrial pacing and premature atrial beats prolong conduction selectively in the normal atrioventricular nodal pathway causing more ventricular excitation via the accessory pathway. This results in further widening of the QRS complex. In our case a pattern of total ventricular pre-excitation was apparent on the electrocardiogram. The stability of QRS configuration during incremental atrial pacing confirmed that the accessory pathway was exciting most or all of the ventricle. This in association with revealed infraHisian block in the normal pathway during nonconducted sinus beats indicated complete heart block rather than second degree block in the nodalHis-Purkinje pathway. Both the aetiology and the duration of the infra-Hisian block were unknown. The second degree block in the accessory pathway appeared to be bradycardia dependent, occurring usually at sinus rates of less than 80 beats per minute. Electrocardiograms were not obtained during attacks of dizziness and higher degrees of block in the accessory pathway were never seen.

Combined conduction disturbances in both the accessory and the normal atrioventricular pathways have only rarely been seen in patients with the Wolff-Parkinson-White syndrome (Seipel et al., 1976). The block in each pathway may be only for anterograde conduction or only for retrograde conduction. Several previous reports have emphasised the superiority of retrograde accessory pathway conduction to anterograde accessory pathway conduction (Coumel et al., 1973; Dreifus et al., 1968; Massumi, 1970). Supranormal conduction down an accessory pathway in association with normal conduction occurring in the nodal-His pathway has also been described (Coumel et al., 1973; McHenry et al., 1966). In our case retrograde conduction of ventricular impulses failed to occur across either the normal or the accessory pathways, nor was supranormal conduction in either pathway seen following premature atrial beats.

Patients with the Wolff-Parkinson-White syndrome and combined conduction disturbances rarely complain of symptoms of bradycardia. One of four patients previously reported by Coumel et al. (1973) presented with an episode of altered consciousness, but this was attributed to sinus node disease rather than an atrioventricular conduction disturbance. In the case reported by Dreifus et al. (1968) symptomatic complete heart block requiring ventricular pacing occurred after ligation of the His bundle for recurrent re-entry tachycardias. Their explanation was that the accessory pathway had also been ligated.

A patient similar to ours with complete block in the normal pathway and second degree block in the accessory pathway has been described (Seipel et al., 1976); the site of this block in the normal pathway was the atrioventricular node, but in contrast the block in our patient was below the His bundle. A common feature was the absence of episodes of loss of consciousness (Adams-Stokes attacks) in spite of frequent episodes of dizziness. This probably depended upon improvement in accessory pathway conduction following reflex increases in the sinus rate. Without the assurance that this protective mechanism would always occur, and because of increasingly frequent attacks of dizziness in our otherwise healthy patient, permanent demand ventricular pacing was undertaken. Electrocardiograms have subsequently shown continuous ventricular pacing without retrograde atrial activation.

The occurrence of rapid ventricular rates caused by $1: 1$ conduction across the accessory pathway during atrial tachycardia is a well recognised complication in some patients with the Wolff-ParkinsonWhite syndrome. This case illustrates a contrasting problem: that of conduction block occurring simultaneously in both the normal and the accessory atrioventricular pathways. The electrophysiological properties of an accessory pathway may vary considerably from moment to moment. When this untrustworthy pathway is the only route of conduction to the ventricle, continuous acceptable function cannot be assumed.

\section{References}

Coumel, P., Gourgon, R., Slama, R., and Bouvrain, Y. (1973). Conduction auriculo-ventriculaire par des fibres de pré-excitation, associée à un bloc complet de la voie nodohissienne: Etude electrocardiographique de quatre cas. Archives des Maladies du Coeur, 66, 285-304.

Dreifus, L. S., Nichols, H., Morse, D., Watanabe, Y., and Truex, R. (1968). Control of recurrent tachycardia of Wolff-Parkinson-White syndrome by surgical ligature of the A-V bundle. Circulation, 38, 1030-1036.

Lev, M., Leffler, W. B., Langendorf, R., and Pick, A. (1966). Anatomic findings in a case of ventricular pre-excitation (WPW) terminating in complete atrioventricular block. Circulation, 34, 718-733.

McHenry, P. L., Knoebel, S. B., and Fisch, C. (1966). The Wolff-Parkinson-White (WPW) syndrome with supernormal conduction through the anomalous bypass. Circulation, 34, 734-739.

Massumi, R. A. (1970). His bundle recordings in bilateral bundle-branch block combined with Wolff-ParkinsonWhite syndrome; antegrade type II (Mobitz) block and 1/1 
retrograde conduction through the anomalous bundle. Circulation, 42, 287-295.

Scherlag, B. J., Lau, S. H., Helfant, R. H., Berkowitz, W. D., Stein, E., and Damato, A. N. (1969). Catheter technique for recording His bundle activity in man. Circulation, 39, 13-18.

Seipel, L., Both, A., Breithardt, G., and Loogen, F. (1976). His bundle recordings in a case of complete atrioventricular block combined with pre-excitation syndrome. American Heart Gournal, 92, 623-629.

Requests for reprints to Dr A. F. Mackintosh, Cardiac Department, King's College Hospital, Denmark Hill, London SE5. 